\title{
Pelatihan Pengembangan Perangkat Pembelajaran Berbasis Teknologi Informatika dengan Bercirikan Joyful Learning
}

\author{
Siti Khoiruli Ummah ${ }^{1}$, Rizal Dian Azmi ${ }^{2}$ \\ ${ }^{1,2}$ Program Studi Pendidikan Matematika, Fakultas Keguruan dan Ilmu Pendidikan, Universitas \\ Muhammadiyah Malang \\ ${ }^{1}$ khoiruliummah@umm.ac.id \\ ²rizaldian@umm.ac.id
}

\begin{abstract}
ABSTRAK
Perangkat pembelajaran merupakan salah satu materi pada Pendidikan Profesi Guru (PPG) yang menuntut peserta PPG, dalam hal ini adalah guru, mengembangkan perangkat pembelajaran tersebut sesuai dengan Kurikulum 2013. Fasilitas yang lengkap di SMP Muhammadiyah Jombang memiliki peluang yang sangat baik untuk mengembangkan pembelajarannya, akan tetapi sebagian besar guru masih memilih untuk mengunakan media pembelajaran cetak daripada menggunakan media berbasis teknologi informasi. Tujuan diadakannya pelatihan ini yaitu guru dapat mengembangkan perangkat pembelajaran berbasis Teknologi Informatika dengan bercirikan Joyful Learning. Program pelatihan ini dilakukan dengan mengadakan workshop terlebih dahulu dengan pemaparan materi perangkat pembelajaran yang sesuai kemudian dilanjutkan dengan pelaksanaan pendampingan. Pendampingan dilaksanakan secara online dengan bantuan aplikasi Edmodo. Hasil pelaksanaan workshop yaitu guru telah menyepakati template RPP sehingga terdapat keseragaman template RPP untuk setiap guru di SMP Muhammadiyah 2 Mojoagung. Selain itu, guru mempunyai gambaran dan rencana penyusunan pembelajaran yang menyenangkan (Joyful Learning) dengan memanfaatkan website "Kahoot!". Workshop telah dilaksanakan dengan hasil yang memuaskan ditinjau dari testimoni dari peserta workshop dan kepala sekolah. Peserta workshop sangat antusias dengan kuis online yang diakses melalui handphone. Program pendampingan telah dilaksanakan selama satu minggu dengan hasil RPP dari setiap guru.
\end{abstract}

Kata kunci: perangkat pembelajaran, joyfull learning, teknologi.

\section{ABSTRACT}

The learning set is one of the materials in Teacher Professional Education (PPG) which requires PPG participants, the theachers, to develop the learning set under the 2013 Curriculum. Complete facilities at SMP Muhammadiyah Jombang have very good opportunities to develop their learning, but most teachers still choose to use print learning media instead of use information technology-based media. This training program is carried out by holding a workshop first with the presentation of appropriate learning material and then continuing with the mentoring. Assistance is carried out online with the help of the "Edmodo" application. The results of the workshop are that the teacher has agreed on the RPP template so that there is uniformity in the RPP template for each teacher in Middle School. Also, the teacher has a picture and plan for compiling Joyful Learning by utilizing the "Kahoot!" Website. The workshop has been carried out with satisfactory results in terms of testimonials from workshop participants and school principals. Workshop participants are very enthusiastic about online quizzes that are accessed via mobile phones. The mentoring program has been carried out for one week with the results is the lesson plans from each teacher.

Keywords: learning set, joyfull learning, technology.

\section{PENDAHULUAN}

Potensi sumber daya sangat memadai di SMP Muhammadiyah di Jombang. Sumber daya berupa laboratorium komputer, aula, jaringan internet yang kuat dan stabil, guruguru yang tidak gagap teknologi serta diijinkannya siswa membawa handphone di sekolah. Peluang yang sangat tinggi apabila dapat memanfaatkan seluruh sumber daya dalam pembelajaran. Di SMP Muhammadiyah Jombang, pembelajaran berlangsung dengan memanfaatkan modul yang dibuat oleh guru. 
Namun, modul tersebut bersifat cetak sehingga membuat siswa merasa jenuh untuk belajar. Laboratorium TI selama ini digunakan untuk uji coba atau tryout UN. Kecepatan internet yang tinggi dimanfaatkan oleh siswa untuk mengaktifkan jaringan internet di handphone dengan keperluan sosial media. Pada jam kosong, guru seringkali terlihat mengobrol dengan topik bahasan yang berbeda-beda namun jarang sekali membahas tentang peningkatan kualitas pembelajaran. Handphone dan jaringan internet juga biasa dimanfaatkan guru untuk berkomunikasi melalui sosial media. Oleh sebab itu, teknologi informasi belum sepenuhnya dimanfaatkan dalam pembelajaran.

Pemanfaatan teknologi dalam pembelajaran matematika tidak selalu berupa media pembelajaran. Teknologi berperan penting dalam peningkatan kualitas pembelajaran tidak hanya sebagai sumber belajar dan media pembelajaran melainkan sebagai penunjang guru untuk merencanakan dan memberikan evaluasi kepada siswa. Selama ini, teknologi komputasi telah popular disebut dengan istilah ICT (Information and Communication Technology) sejak Tahun 1992 dimana sebelumnya disebut dengan istilah IT (Information Technology) pada Tahun 1980-an (Muchamad, Mawarti, Santoso, \& Kom, 2015). ICT atau yang lebih dikenal dengan Teknologi Informasi dan Komunikasi, mencakup jaringan internet, sarana dan prasarana telekomunikasi, sarana dan prasarana teknologi, media, penyiaran, pusat dokumentasi dan perpustakaan, penyedia informasi yang komersial, layanan informasi berbasis internet, dan aktivitas komunikasi dan informasi lainnya (Matthew, Joro, \& Manasseh, 2015). Produk dari ICT yang dapat dikaitkan dengan pendidikan sangat beragam. Contoh produk yang digunakan dalam pendidikan antara lain: (1) telekonferensi, (2) email, (3) penyiaran radio, (4) tayangan TV, (5) konsultasi interaktif melalui radio, (6) kaset pita, (7) flashdisk, (8) harddisk eksternal, (9) microSD, dan lain-lain (Muchamad et al., 2015).

ICT mempunyai peranan penting dalam pendidikan yaitu sebagai inovasi, akselerasi, motivasi siswa, dan bantuan kepada sekolah agar menjadi maju (Matthew et al., 2015). Selama ini, penggunaan ICT dalam pendidikan terbatas pada peranannya sebagai sumber informasi atau sumber belajar, media pembelajaran atau yang lebih sering digunakan yaitu power point, dan pengiriman tugas melalui email. Sebagai seorang guru sudah seharusnya meningkatkan kualitas pembelajarannya terutama perencanaan pembelajaran. ICT mempunyai hubungan erat dengan siswa terutama melalui penggunaan handphone. Kenyataannya, seringkali terlihat siswa mengoperasikan handphone saat pembelajaran berlangsung. Siswa seringkali menggunakan handphone untuk berkomunikasi melalui social media. Selain itu, siswa juga seringkali menggunakan handphone atau lebih khususnya pada pencarian khusus menggunakan Google untuk menyelesaikan tugas. Seringnya siswa yang mengakses internet melalui handphone seharusnya dapat diintegrasikan dalam pembelajaran agar dapat meningkatkan dan mengembangkan lingkungan pembelajaran yang mendukung aktivitas belajar siswa. Agar integrasi internet dengan pembelajaran dapat berjalan efektif, maka guru harus dapat terlibat dalam pembelajaran yang berbasis teknologi.

Keterlibatan guru dalam pembelajaran berbasis teknologi antara lain: (1) mengenalkan penggunaan ICT dalam bentuk internet kepada siswa, (2) mengontrol penggunaan internet pada siswa selama pembelajaran, dan (3) menyiapkan siswa untuk generasi berbasis ICT untuk penunjang karirnya di masa yang akan datang (Thakur, 2017). Salah satu produk ICT yang paling popular yaitu e-learning. E-learning dapat dimanfaatkan sebagai sarana komunikasi efektif pada pembelajaran jarak jauh dalam bentuk video conference (Lin \& Md.Yunus, 2012). Manfaat e-learning selanjutnya yaitu sebagai bantuan siswa untuk memahami pembelajaran, terfokus pada materi dan untuk mengkaji dan mereview pembelajaran yang telah disampaikan sebelumnya serta dapat memotivasi siswa belajar dan memberikan reaksi positif terhadap pembelajaran matematika (Matthew et al., 2015).

Permasalahan mitra berkaitan dengan pemanfaatan teknologi informasi dalam pembelajaran. Pemanfaatan teknologi informasi dalam pembelajaran menjadi fokus persoalan yang disepakati oleh pengusul dan mitra. Pemanfaatan teknologi informasi selanjutnya diwujudkan dalam bentuk pembelajaran bercirikan Joyful Learning. Joyful Learning merupakan suatu pengalaman belajar yang dapat membuat siswa senang dalam mengikuti proses belajar-mengajar (Yusra \& Saragih, 2016). Pembelajaran yang menyenangkan atau Joyful Learning menitikberatkan pada pembelajaran yang 
sepenuhnya melibatkan siswa tanpa tekanan dan paksaan. Guru berperan sebagai fasilitator yang melibatkan siswa untuk belajar secara mandiri dan sesuai dengan kreativitasnya (Proity, 2015). Dalam hal ini, guru juga dapat senang dalam pembelajaran karena dapat mengembangkan kreativitasnya dalam menyampaikan materi (Chopra \& Chabra, 2013). Permasalahan spesifik pada mitra yaitu belum adanya pelatihan pembuatan perangkat pembelajaran yang sesuai kurikulum. Pemanfaatan Joyful Learning di SMP Muhammadiyah Jombang belum pernah ada. Handphone dan internet juga belum dimanfaatkan dalam pembelajaran. Hal ini dijadikan sebagai spesifikasi permasalahan yaitu pembuatan perangkat pembelajaran berbasis TI bercirikan Joyful Learning.

\section{METODE KEGIATAN}

Metode yang ditawarkan untuk menyelesaikan persoalan mitra yaitu memberikan pelatihan dan pendampingan pembuatan perangkat pembelajaran bagi guru SMP Muhammadiyah 2 Mojoagung. Pelatihan dan pendampingan pembuatan e-learning akan berlangsung selama empat kali pertemuan sampai terciptanya e-learning dalam bentuk aplikasi Edmodo pada setiap guru.

Tahap awal dari kegiatan pengabdian yaitu observasi ke sekolah untuk melakukan analisis awal. Analisis awal dilakukan untuk mencari tahu tentang kendala pembelajaran matematika di sekolah terkait bentuk evaluasinya. Selain itu, observasi tentang ketersediaan layanan internet dan gadget pada guru dan siswa. Langkah selanjutnya yaitu pembuatan instrument pelatihan. Instrumen pelatihan berupa handout dengan mengacu pada literature yang berkaitan dengan pembelajaran berbasis TI bercirikan Joyful Learning.

Selanjutnya dilakukan sosialisasi awal yang dilakukan sebanyak satu pertemuan dengan materi pengenalan perangkat pembelajaran sesuai K-13 dan macammacamnya. Pada kegiatan ini, guru diperkenalkan tentang penggunaan internet yang diintegrasikan dalam pembelajaran melalui handphone. Selain itu, kegiatan sosialisasi juga digunakan untuk mengidentifikasi ada atau tidaknya email pada guru. Apabila belum punya, maka guru didampingi untuk membuat email terlebih dahulu. Pelatihan pembuatan perangkat pembelajaran dilakukan sebanyak empat pertemuan.

\section{HASIL \& PEMBAHASAN}

\section{Gambaran Umum Profil Mitra}

Sosialisasi didampingi oleh wakil kepala sekolah bidang kurikulum. Waka kurikulum menjelaskan selama ini guru membuat perangkat pembelajaran hanya apabila ada pengawas yang akan datang atau diminta oleh Dinas Pendidikan. Guru juga belum terampil dalam membuat media pembelajaran secara mandiri. Kendala yang dihadapi oleh guru ketika mengimplementasikan teknologi informatika pada pembelajaran yaitu kurangnya sarana pembelajaran misalnya LCD di setiap kelas. LCD yang dimiliki oleh sekolah hanya ditempatkan di Laboratorium IPA sebanyak satu dan Laboratorium komputer sebanyak satu. Kondisi SMP 2 Mojoagung diberikan pada Gambar 1.

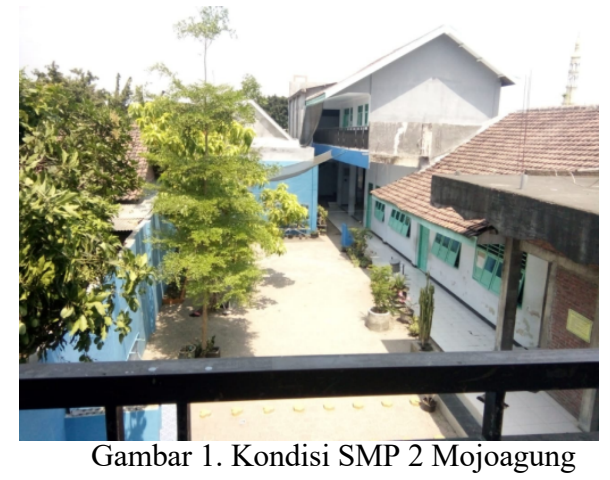

Terdapat enam sekolah lain yang ingin mengikuti pelatihan ini. Keenam sekolah tersebut disampaikan oleh kepala sekolah bahwa juga memerlukan pelatihan namun pada saat tanggal workshop disampaikan, tidak semua sekolah dapat mengikuti. Ada dua sekolah yang bersedia bergabung dalam acara workshop yaitu SMP Muhammadiyah 3 Kesamben dan SMP Muhammadiyah 4 Sumobito. Jumlah guru yang mengikuti pelatihan ini adalah 28 guru.

\section{Proses Pelaksanaan}

Langkah awal dari pelaksaan pelatihan penyusunan perangkat pembelajaran yaitu penyusunan instrument pelatihan. Instrumen yang akan digunakan adalah Angket Evaluasi Awal Peserta Pelatihan, Power Point dan Template RPP

Angket dibuat dalam bentuk online menggunakan website "Typeform". "Typeform" merupakan website penyedia jasa kuis online secara gratis. Selain kuis, user dapat membuat kuisioner online. 
Isi angket disesuaikan dengan kebutuhan materi pelatihan untuk menyeleksi bagian mana yang paling penting untuk disampaikan pada workshop. Misalnya, untuk media pembelajaran, pilihan dapat lebih dari satu namun tim pengabdian akan melatih guru membuat media pembelajaran yang jarang atau sulit dikembangkan oleh guru.

Angket ini diberikan untuk diisi oleh guru sebelum materi workshop disampaikan. Guru diminta mengakses angket melalui link yaitu http://gg.gg/exazq yang diberikan pada slide kemudian guru mengetikkan URL pada browser masing-masing. Tampilan angket online ditunjukkan pada Gambar 2.

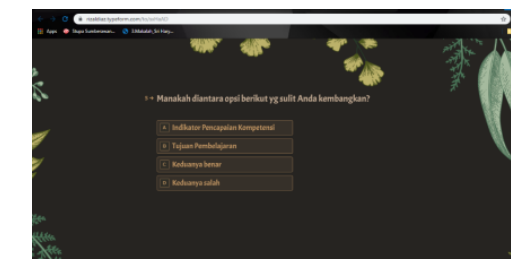

Gambar 2. Angket Online dengan "Typeform”

Guru sangat antusias untuk megisi kuisioner seperti terlihat pada Gambar 3.Adapun hasil dari angket yang diperoleh yaitu:

a. Sebanyak $73.7 \%$, guru membuat RPP setiap awal semester dan sebanyak $21.1 \%$ membuat RPP setiap awal tahun pelajaran

b. Sebanyak $68.4 \%$ guru menjawab sudah ada template dari sekolah dan sebanyak $31.6 \%$ menjawab sekolah belum menyediakan template.

c. Sebanyak $68.4 \%$ guru tidak membuat RPP secara mandiri dan $31.6 \%$ guru membuat RPP secara mandiri.

d. Sebanyak $73.7 \%$ guru berupaya mendiskusikan capaian materi dengan teman sejawat dan $26.3 \%$ tidak mendiskusikan hal tersebut.

e. Sebanyak 52.6\% guru kesulitan dalam mengembangkan indikator pembelajaran dan hanya $5.3 \%$ guru yang kesulitan untuk mengembangkan tujuan pembelajaran. Sebanyak $42.1 \%$ guru kesulitan mengembangkan indikator dan tujuan pembelajaran.

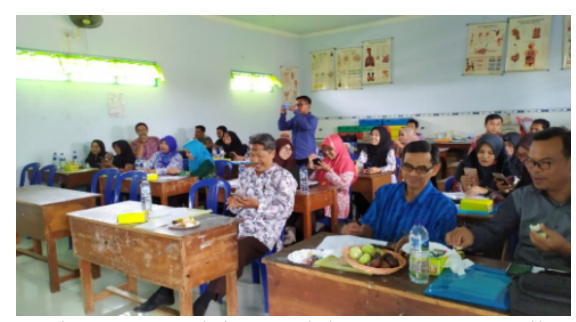

Gambar 3. Pengisian Kuisioner Secara Online f. Sebanyak $94.7 \%$ guru pernah membuat media pembelajaran secara mandiri dan hanya $5.3 \%$ guru yang tidak pernah membuat media pembelajaran.

g. Guru lebih sering mengembangkan media dalam bentuk Power Point dengan jumlah responden 12 orang. Selain itu, guru ada yang lebih sering mengembangkan media dalam bentuk LKPD.

h. Sebanyak $52.6 \%$ guru sudah terampil mengoperasikan komputer namun masih ada $47.4 \%$ guru belum terampil dan terbiasa mengoperasikan komputer.

i. Walaupun guru banyak yang terampil pengoperasikan komputer, namun sebanyak $78.9 \%$ guru tidak pernah membuat kuis secara online. Hanya $21.1 \%$ guru yang pernah membuat kuis secara online.

j. Guru sering menggunakan metode ceramah dengan pemberian tugas yaitu sebanyak $94.7 \%$ dan tidak ada yang pernah menggunakan pembelajaran dengan mengintegrasikan Teknologi Informatika.

Berdasarkan hasil kuisioner yang diberikan di awal pelatihan, dapat diketahui bahwa pada proses pembuatan RPP, guru kesulitan merumuskan indikator. Setelah diadakan tanya-jawab untuk mengkonfirmasi hasil kuisioner, guru kesulitan menentukan KKO, terlebih jika diminta instrumen pembelajaran yang menekankan pada soal bertipe HOTS. Pembelajaran yang biasa diimplementasikan seringkali menggunakan metode ceramah. Beberapa guru saja yang menggunakan Power point dengan pemberian tugas. Hal ini disebabkan karena sekolah tidak mempunyai sarana yang memadai untuk mengintegrasikan TI pada pembelajaran. Guru lebih dominan menggunakan ceramah disertai pemberian tugas.

Berkaitan dengan pembelajaran yang terintegrasi dengan TI, guru sudah mampu mengoperasikan komputer, terbukti guru mampu membuat media dalam bentuk power point. Hanya beberapa guru saja yang pernah membuat kuis secara online. Guru menyampaikan melalui tanya-jawab bahwa pembuatan power point tidak pernah diimplementasikan melainkan hanya sebagai pemenuhan syarat pembuatan perangkat pembelajaran yang akan dimonitoring dan dievaluasi oleh pengawas.

Pelatihan diawali dengan materi pembuatan RPP. Pemateri yaitu Siti Khoiruli 
Ummah, M.Pd menyampaikan kaidah-kaidah yang harus dipenuhi untuk membuat RPP sesuai Permendikbud Nomor 22 Tahun 2016 melalui tayangan power point. Peserta sangat antusias menyimak, bertanya jawab, dan meminta pendapat tentang permasalahan yang dihadapi oleh guru ketika membuat RPP. Adapun permasalahan yang muncul dari guru ketika membuat RPP antara lain:

1. Guru belum terbiasa menyertakan KD dari KI-4 yaitu ranah keterampilan

2. Guru masih sering menggunakan KKO "memahami" untuk mengembangkan indikator pembelajaran

3. Guru belum mencantumkan stimulus pada setiap indikator pembelajaran

4. Guru belum dapat membedakan penulisan indikator pembelajaran dan tujuan pembelajaran

5. Guru belum menerapkan kaidah ABCD (Audience, Behavior, Condition, Degree) ketika menyusun tujuan pembelajaran

6. Guru belum dapat mengembangkan kegiatan pembelajaran sesuai sintaks model pembelajaran yang digunakan

7. Guru biasa membuat soal dari Lembar Kerja Siswa (LKS) secara adopsi dari penerbit swasta lainnya.

Pelatihan berlangsung antusias saat pemberian materi berupa indikator pembelajaran. Beberapa guru menyampaikan bahwa indikator pembelajaran tidak perlu memuat stimulus. Stimulus perlu dicantumkan ketika tujuan pembelajaran dikembangkan. Tim pengabdian selanjutnya menunjukkan Permendikbud Nomor 22 Tahun 2016 dan Referensi berupa Pedoman Pembuatan Instrumen Evaluasi Pembelajaran yang dikembangkan Kemdikbud. Berdasar referensi, indikator pembelajaran harus memuat Subyek, Stimulus, dan perilaku. Stimulus yaitu rangsangan yang diberikan guru untuk pencapaian indikator oleh siswa. Stimulus dapat berupa pemberian media, pemberian bahan diskusi atau diskusi klasikal.

Pada saat pengembangan tujuan pembelajaran, guru terbiasa mengcopy pernyataan dari indikator pembelajaran. Hanya saja, guru biasa menambahkan di awal kalimat yaitu: "dengan pemberian LKS, siswa dapat:" kemudian menambahkan pernyataan indikator pembelajaran yang telah dibuat sebelumnya. Guru juga menyampaikan bahwa selama ini perumusan tujuan pembelajaran tidak sesuai jumlahnya dengan indikator pembelajaran. Selanjutnya, guru juga menyampaikan bahwa indikator dan tujuan pembelajaran untuk mencapai KI-4 yaitu ranah keterampilan tidak pernah dikembangkan. Kalaupun dikembangkan, guru biasa menuliskan tidak spesifik dalam penyebutan permasalahan yang digunakan.

Pelatihan dengan sistem tanya-jawab berlangsung secara aktif. Hal ini dilihat dari respon guru saat diminta menjawab pertanyaan atau menanyakan hal-hal yang belum dipahami. Ketika guru meminta penjelasan tentang tabel taksonomi Bloom, guru menanyakan bagaimana merumuskan indikator untuk ranah sikap dan sosial. Tim pengabdian kemudian mencarikan Tabel Taksonomi Bloom yang sudah dilengkapi dengan KKO ranah sikap dan sosial. Dengan menggunakan tabel taksonomi Bloom, guru menyampaikan bahwa perumusan indikator pembelajaran mudah untuk dikembangkan dengan melihat dan mengadopsi Taksonomi Bloom. Di akhir pelatihan pembuatan RPP, guru diminta menyimak video pembelajaran Abad 21 yang menunjukkan bahwa teknologi informatika dan komunikasi sangat mendukung pembelajaran di level sekolah dasar. Guru antusias dan berkomentar bahwa video tersebut sangat sulit diterapkan di Indonesia mengingat tidak semua sekolah dilengkapi dengan sarana teknologi dan jaringan internet yang memadai. Kegiatan ini diperlihatkan pada Gambar 4.

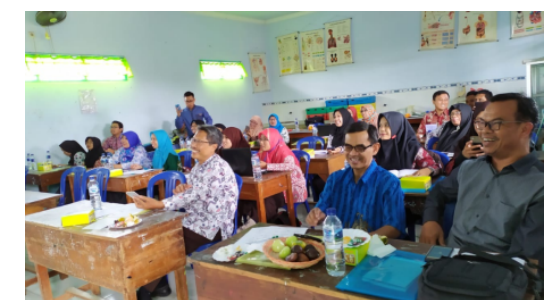

Gambar 4. Antusias Guru Ketika Menyimak Tayangan Video Pembelajaran Abad 21

Pelatihan selanjutnya yaitu pelatihan pembuatan kuis online oleh Rizal Dian Azmi, M.Sc. Kuis online yang digunakan yaitu menggunakan bantuan website penyedia layanan kuis online gratis yaitu Kahoot!. Tim pengabdian sudah menyiapkan kuis online yang diujicobakan kepada guru terlebih dahulu untuk mengetahui respon awal guru terhadap pembuatan kuis online.

Peserta workshop membuka browser pada masing-masing handphone dengan URL kahoot.it. Selanjutnya, peserta workshop diminta memasukkan PIN yang sudah dibuat oleh tim pengabdian agar bisa mengakses kuis. Kuis menggunakan arahan pemateri dan sesuai 
instruksi pemateri. Setelah soal ditayangkan, peserta workshop menjawab menggunakan handphone masing-masing menggunakan objek gambar yang disesuaikan dengan option pada layar LCD. Misal, option berupa "BENAR" dan "SALAH" maka yang muncul pada layar handphone bukan berupa teks melainkan objek belah ketupat dan persegi dengan warna yang berbeda. Selanjutnya, peserta workshop dapat melihat respon jawabannya melalui teks "Anda Benar" atau "Anda Salah". Kemudian, pada layar LCD terdapat skor tertinggi yang muncul dari kelas tersebut. Skor tertinggi disesuaikan dengan kecepatan dan ketepatan jawaban. Peserta workshop sangat antusias dan tertantang untuk melanjutkan sesi soal selanjutnya. Gambar 5 berikut menunjukkan ekspresi peserta workshop saat mengakses kuis online.
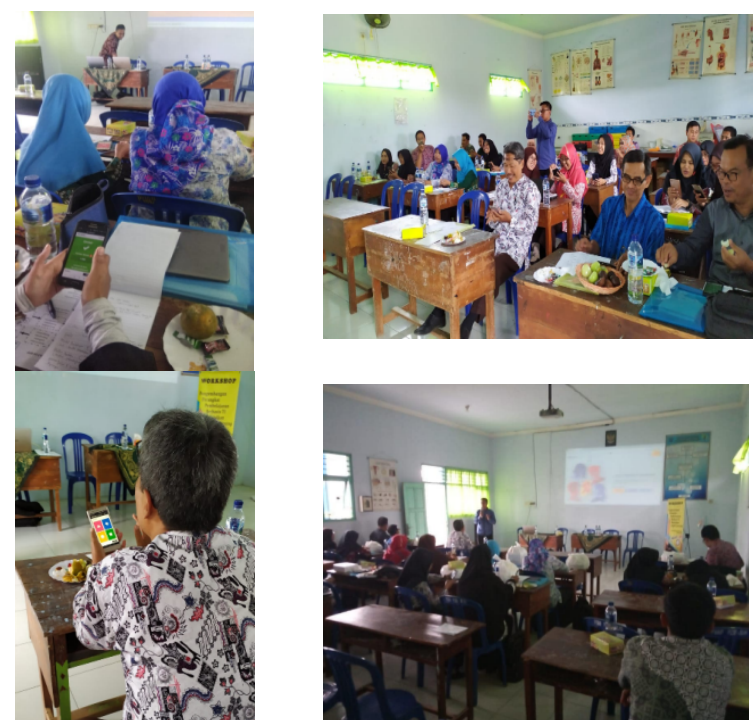

Gambar 5. Ekspresi dan Antusias Guru Mengoperasikan Kuis Online

Setelah pelatihan materi RPP dan media, pelatihan dilanjutkan dengan pembuatan akun melalui Edmodo. Akun ini merupakan sarana komunikasi guru dengan tim pengabdian untuk penugasan RPP. Edmodo dipilih karena sangat mudah untuk dioperasikan dan dapat diinstal melalui Google Apps. Hal ini akan membuat guru dapat mengikuti aktivitas yang dibagikan oleh Tim Pengabdian melalui notifikasi pada handphone.

Berdasar hasil wawancara dengan peserta pelatihan tersebut, peserta workshop terbantu untuk mengembangkan perangkat pembelajaran berupa RPP dan kuis. Peserta juga memerlukan tindak lanjut workshop dan bantuan tim pengabdian untuk memfasilitasi diskusi apabila ada kesulitan dalam keseluruhan pengerjaan perangkat pembelajaran. sekolah dan guru sangat antusias mengikuti workshop untuk tambahan materi dan adanya pendampingan pembuatan perangkat pembelajaran. Sekolah juga memerlukan workshop tambahan tentang instrument evaluasi pembelajaran untuk semua sekolah muhammadiyah se-Kabupaten Jombang.

\section{KESIMPULAN \& SARAN}

\section{Kesimpulan}

Melalui program pengabdian kepada masyarakat dalam bentuk pelatihan pembuatan perangkat pembelajaran berbasis TI dan bercirikan Joyful Learning, peserta workshop mempunyai gambaran RPP dengan pendekatan saintifik dan bercirikan Joyful Learning. Adapun teknologi informatika yang terintegrasi dalam pembelajaran dapat diwujudkan dalam bentuk media pembelajaran berupa power point atau post test dalam bentuk kuis online. Perubahan yang terjadi pada mitra yaitu mitra mampu merumuskan indikator pembelajaran dengan susunan subyek, stimulus dan perilaku dengan mengadopsi KKO pada Taksonomi Bloom. Selain itu, mitra dalam hal ini guru, mampu merumuskan tujuan pembelajaran dengan memperhatikan kaidah Audience, Behavior, Condition, dan Degree dimana sebelumnya hanya menuliskan audience dan condition.

\section{Saran}

Saran yang dapat dipaparkan yaitu perlunya tindak lanjut berupa pendampingan pembuatan perangkat pembelajaran secara online maupun offline. Selain itu, mitra perlu diberikan workshop tentang penyusunan instrument evaluasi pembelajaran berbasis HOTS atau soal dengan level kognitif tingkat tinggi sebagai wujud kesesuaian dengan tuntutan Kurikulum 2013.

\section{DAFTAR PUSTAKA}

Chopra, \& Chabra, S. (2013). Digantar in India: a Case Study for Joyful Learning. Journal of Unschooling \& Alternative Learning, 7(13), 28-44.

Lin, C. P., \& Md.Yunus, M. (2012). ESL Teacher and ICT:Teachers' Perception. Advances in Language and Literary Studies, 3(1), 119-128. https://doi.org/10.7575/aiac.alls.v.3n.1p.1 19

Matthew, D., Joro, I. D., \& Manasseh, H. (2015). The Role of Information 
Communication Technology in Nigeria Educational System, 2(2), 64-68.

Muchamad, M. K., Mawarti, A. D., Santoso, H., \& Kom, M. (2015). Australian Journal of Basic and Applied Sciences Analisis Development and Implementation Media Education of Matematic Achievement of Student Learning ( Object: Student 6th Grade in Semarang ). Australian Journal of Basic and Applied Sciences, 9(9), 37-42.

Proity, S. H. (2015). Effect of joyful teaching on grade IV students" academic performance in science. International Journal of Science and Research (IJSR) ISSN (Online Index Copernicus Value Impact Factor, 4(10), 1232-1240.

Thakur, V. (2017). ICT Transforming Teaching \& Learning System, (July 2016)

https://doi.org/10.18535/ijsrm/v4i7.02

Yusra, D., \& Saragih, S. (2016). The Profile of Communication Mathematics and Students' Motivation by Joyful Learningbased Learning Context Malay Culture. British Journal of Education, Society \& Behavioural Science, 15(4), 1-16. https://doi.org/10.9734/BJESBS/2016/25 521 